\title{
Griseococcin (1) from Bovistella radicata (Mont.) Pat and antifungal activity
}

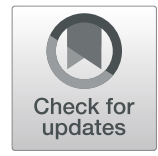

Yong Ye ${ }^{1,2}$, Qinghua Zeng ${ }^{1,2}$ and Qingmei Zeng ${ }^{1,2^{*}}$

\begin{abstract}
Background: To evaluate the antimicrobial and microbicidel activity of B. radicata fermentation broth, the broth was purified by DEAE-cellulose and sephadex LC-20 column. The compounds were submitted to spectral analyses (HPLC, FT-IR, 1D and 2D NMR etc.).

Results: The purified compounds were identified as the Griseococcin(s) which were naphthoquinone derivatives, the Chemical formula and MW of Griseococcin (1) was determined as $\mathrm{C}_{37} \mathrm{O}_{10} \mathrm{H}_{43} \mathrm{~N}$ and 661 Da. only Griseococcin (1) has good antimicrobial activity among the Griseococcin(s). The zone of inhibition (ZOI), minimum inhibitory concentration (MIC) and minimum bactericidal concentration (MBC) or minimum fungicidal concentration (MFC) of Griseococcin (1) were used to investigate the antimicrobial activity. Antifungal activity of Griseococcin (1) was significant, especially for main pathogenic fungus Trichophyton rubrum and Trichophyton mentagrophytes, MFC/MIC of Griseococcin (1) was 1, while MFC/MIC of postive control was greater than 4, the fungicidal effect of Griseococcin (1) was better than that of positive control.

Conclusions: In this paper, the secondary metabolite compound Griseococcin (1) from B. radicata was purified. The purified compound can restrain main pathogens (T. rubrum and T. mentagrophytes) leading to tinea pedis. The antifungal activity of Griseococcin (1) was similar to that of the positive control and the fungicidal effect of Griseococcin (1) was better than that of positive control, it might be suitable for pharmaceutical industries.
\end{abstract}

Keywords: Griseococcin, LH-20, DEAE, 1D NMR, 2D NMR, HPLC, FT-IR

\section{Background}

Tinea pedis is a chronic fungal infection of the feet [1]. Patients that have tinea pedis may be affected by several pathogens, including filamentous fungi named Trichophyton rubrum and Trichophyton mentagrophytes [2], as well as a yeast named Candida albicans [3]. T. rubrum is the main pathogenic fungi for tinea pedis, having a prevalence as high as $80 \%$ among all tinea-pedis associated pathogenic microbes [4]. Traditionally, to treat tinea pedis, synthetic fungicides such as fluconazole, itraconazole, echinocandins [5], and miconazole nitrate,

\footnotetext{
* Correspondence: zengqingmei@hfut.edu.cn

'School of Food and Biological Engineering, Hefei University of Technology, Hefei 230009, Anhui, China

${ }^{2}$ Engineering Research Center of Bio-Process, Ministry of Education, Hefei University of Technology, Hefei 230009, Anhui, China
}

either by oral medication or external use [6], have been used to treat this disease. Vermes et al. (2000) found that flucytosine and AMB (amphotericin B) were moderately effective in fighting against invasive fungal infections [7-9]. Similar studies on itraconazole have demonstrated that it is effective against fungal infections [10]. However, due to side effects or the continuous drug resistance, some oral medications are unsafe for patients [11], and these chemicals also cause potential deleterious effects on the environment due to their residues [12, 13]. In general, plant natural products have been for decades one of the most successful sources of drugs to treat infectious diseases [14] and natural products extracted represent a rich resource for screening bioactive compounds [15].

Puffballs are widely distributed in many provinces of China, and are various by more than 100 species [16].

(c) The Author(s). 2020 Open Access This article is licensed under a Creative Commons Attribution 4.0 International License, which permits use, sharing, adaptation, distribution and reproduction in any medium or format, as long as you give appropriate credit to the original author(s) and the source, provide a link to the Creative Commons licence, and indicate if changes were made. The images or other third party material in this article are included in the article's Creative Commons licence, unless indicated otherwise in a credit line to the material. If material is not included in the article's Creative Commons licence and your intended use is not permitted by statutory regulation or exceeds the permitted use, you will need to obtain permission directly from the copyright holder. To view a copy of this licence, visit http://creativecommons.org/licenses/by/4.0/ The Creative Commons Public Domain Dedication waiver (http://creativecommons.org/publicdomain/zero/1.0/) applies to the data made available in this article, unless otherwise stated in a credit line to the data. 
Calvatia gigantean (Batsch ex Pers) Lloyd, Calvatia lilacina (Mont.et Berk.) Lloyd, Lasiosphaera fenzlii Reich, Lycoperdon pyriforme Schaeff::pers, Bovistella radicata (Mont.) Pat, Handkea utriformis (HU), H. excipuliformis $(H E)$, and Vascellum pratense (VP) are all common medicinal puffballs. Although no longer edible in their mature state (because of their powdery consistency), these puffballs have been shown to be a source of active compounds of various biological activities. Puffballs are believed to have several therapeutic properties when used medicinally: hemostasis [17], cough relief [18], suppression of cell division, and antitumor [19] and antimicrobial [20] properties. Petrović P, et al. reported noticeable antimicrobial activity diversity for the methanol extracts obtained from Handkea utriformis (HU), H. excipuliformis (HE), and Vascellum pratense (VP) [21]. Specimen (Bovistella radicata (Mont.) Pat) was dried and deposited in the Institute of Biology, School fo Food and Biological Engineering, Hefei University of Technology (HFUT), China.

The aim of the present study was to evaluate the antimicrobial activity of Griseococcin (1) extracted from $B$. radicata fermentation broth. The antimicrobial and microbicidel activities were evaluated in terms of their minimum inhibitory concentration (MIC), minimum fungicidal concentration (MFC) or minimum bactericidal concentration (MBC) and zone of inhibition (ZOI) values [22], the physico-chemical characterization (HPLC, UV, FT-IR) of Griseococcin (1) and the chemical constituents responsible for this activity were also studied (1D and 2D NMR).

\section{Results}

\section{Fermentation, extraction and purification of active} compound from $B$. radicata

$20 \% \mathrm{NaCl}$ elution fraction from fermentation broth of $B$. radicata was named as SPAF by DEAE-cellulose column. The strongest antimicrobial activity fraction from SPAF was Griseococcin (1) by Sephadex LH-20 column. The $U_{\text {max }}$ of all the fraction was $215 \mathrm{~nm}$, the HPLC chromatograms of SPAF and Griseococcin (1) were shown in Fig. 1(a b). The chromatogram of B showed a single and symmetrical peak for Griseococcin (1) (Fig. 1b).

\section{D and 2D NMR of Griseococcin (1)}

Griseococcin (1) was isolated as a white amorphous solid powder with the molecular formula of $\mathrm{C}_{37} \mathrm{H}_{43} \mathrm{NO}_{10}$ derived from the high-resolution electrospray ionization mass spectrum (HR-ESI-MS). The complete assignments

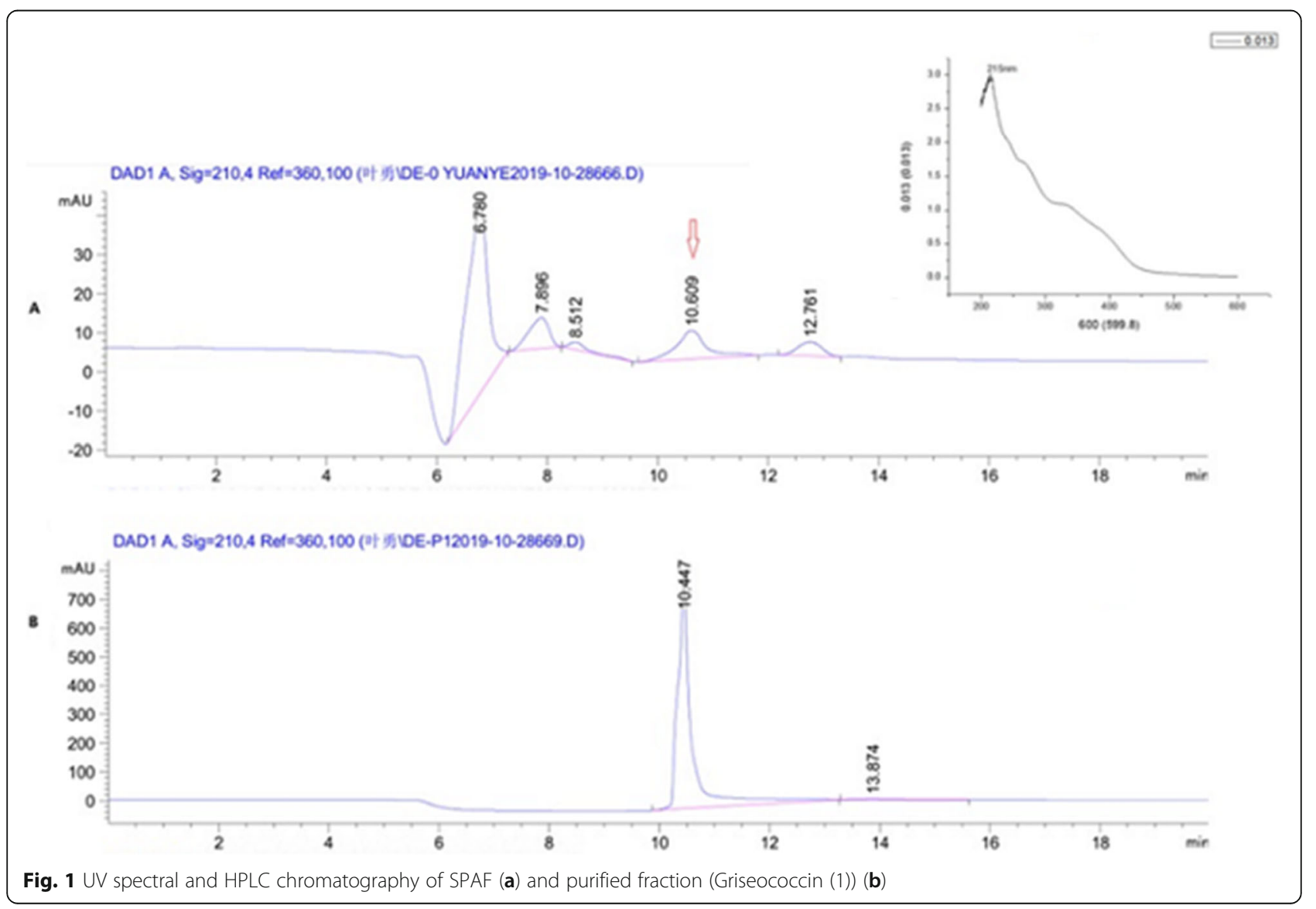


for all protons and carbons were shown in Table 1. The ${ }^{13} \mathrm{C}$ NMR spectra of Griseococcin (1) displayed signals of thirty seven carbons, including five carbonyl carbons ( $\delta \mathrm{C} 215.7-175.1)$, five aromatic/olefinic methine carbons ( $\delta \mathrm{C} 128.86, \delta \mathrm{C} 215.7-175.1)$, seven non-protonated aromatic/olefinic carbons ( $\delta C$ 161.06-109.99), four methyl carbons $(\delta \mathrm{C} 20.27))$, and four olefin carbons $(\delta \mathrm{C}$ 166.01). The ${ }^{1} \mathrm{H}$ NMR spectrum of 1 in $\mathrm{D}_{2} \mathrm{O}$ exhibited signals of four methyls at $\delta \mathrm{H} 2.14\left(3 \mathrm{H}, \mathrm{s}, \mathrm{H}-14^{\prime}\right), \delta \mathrm{H}$ $2.12\left(3 \mathrm{H}, \mathrm{s}, \mathrm{H}-15^{\prime}\right), \delta \mathrm{H} 1.06\left(3 \mathrm{H}, \mathrm{s}, \mathrm{H}-16^{\prime}\right)$ and 1.07 $\left(3 \mathrm{H}, \mathrm{s}, \mathrm{H}-17^{\prime}\right)$, five aromatic protons $\delta \mathrm{H} 7.80(1 \mathrm{H}, \mathrm{s}, \mathrm{H}-$ 1), $\delta \mathrm{H} 7.93(1 \mathrm{H}, \mathrm{s}, \mathrm{H}-5), \delta \mathrm{H} 7.72(1 \mathrm{H}, \mathrm{s}, \mathrm{H}-6), \delta \mathrm{H} 7.81$ $(1 \mathrm{H}, \mathrm{s}, \mathrm{H}-8)$ and $7.66(1 \mathrm{H}, \mathrm{s}, \mathrm{H}-12)]$, four hydroxyl groups at $\delta \mathrm{H} 8.37(1 \mathrm{H}$, br s, 4'-OH), $\delta \mathrm{H} 7.81(1 \mathrm{H}$, br s, $\left.9^{\prime} \mathrm{OH}\right)$ and $\delta \mathrm{H} 7.80\left(1 \mathrm{H}\right.$, br s, $\left.11^{\prime}-\mathrm{OH}\right)$ and $9.63(1 \mathrm{H}, \mathrm{br}$ s, $\left.13^{\prime}-\mathrm{OH}\right)$.

The structure of Griseococcin (1) was deduced by comprehensive analysis of ${ }^{1} \mathrm{H}-{ }^{1} \mathrm{HCOSY}, \mathrm{HMBC}$, and HSQC spectra (Fig. 2a). In Griseococcin (1), the naphthoquinone substructure could be identified by the observation of HMBC correlations from $\mathrm{H}-8(\delta \mathrm{H} 7.80)$ to $\mathrm{C}-6(\delta \mathrm{C} 137.21), \mathrm{C}-4(\delta \mathrm{C} 138.60)$ and $\mathrm{C}-13(\delta \mathrm{C}$ $30.18)$, from $\mathrm{H}-1$ ( $\delta \mathrm{H} 7.81)$ to $\mathrm{C}-3$ ( $\delta \mathrm{C} 175.11), \mathrm{C}-12(\delta \mathrm{C}$ $166.07)$ and $\mathrm{C}-1^{\prime}(\delta \mathrm{C} 28.40)$, from $\mathrm{H}-5(\delta \mathrm{H} 7.93)$ to $\mathrm{C}-3$ ( $\delta \mathrm{C} 175.11)$ and $\mathrm{C}-9(\delta \mathrm{C} 138.56)$, from $\mathrm{H}_{2}-13(\delta \mathrm{H} 1.07)$ to $\mathrm{C}-8(\delta \mathrm{C} 135.45)$ and $\mathrm{C}-6(\delta \mathrm{C} 137.21)$, from $\mathrm{H}_{3}-14{ }^{\prime}$ $(\delta \mathrm{H} 1.85)$ to $\mathrm{C}^{-2}{ }^{\prime}(\delta \mathrm{C} 215.7)$ and $\mathrm{C}-4^{\prime}(\mathrm{OH})(\delta \mathrm{C} 73.60)$, from $\mathrm{H}_{3}-15^{\prime}(\delta \mathrm{H} 2.11)$ to $\mathrm{C}^{\prime} 6^{\prime}(\delta \mathrm{C} 215.70)$ and $\mathrm{C}-4{ }^{\prime}$ $(\mathrm{OH})(\delta \mathrm{C} 73.60)$, from $\mathrm{H}_{2}-7^{\prime}(\delta \mathrm{H} 1.08)$ to $\mathrm{C}^{\prime} 9^{\prime}(\delta \mathrm{C}$ 71.25 ) and $\mathrm{C}-13^{\prime}(\delta \mathrm{C} 71.18)$. The ${ }^{1} \mathrm{H},{ }^{1} \mathrm{H}$ three-bond couplings observed in the COSY spectrum from $\mathrm{H}-8$ ' $(\delta \mathrm{H} 1.94)$ to $\mathrm{H}-9^{\prime}(\delta \mathrm{H} \mathrm{3.62})$, from $\mathrm{H}-10^{\prime}(\delta \mathrm{H} 1.29)$ to $\mathrm{H}-11^{\prime}\left(\delta \mathrm{H}\right.$ 3.49), from $\mathrm{H}-12^{\prime}(\delta \mathrm{H} 1.73)$ to $\mathrm{H}-13^{\prime}(\delta \mathrm{H}$ 3.51 ), together with the chemical shifts of the ${ }^{13} \mathrm{C}$ resonances $\left(C-8^{\prime}-13^{\prime}\right)$ observed at alternating higher and lower fields, revealed the presence of cyclohexane with alternating hydroxyl and methyl groups. ${ }^{1} \mathrm{H}-{ }^{1} \mathrm{H}$ COSY correlations from $\mathrm{H}_{2}-13(\delta \mathrm{H} 1.07, \mathrm{~m})$ to $\mathrm{H}_{2}-14(\delta \mathrm{H} 3.62$, $\mathrm{m})$, from $\mathrm{H}_{2}-14(\delta \mathrm{H} 3.62, \mathrm{~m})$ to $\mathrm{H}_{2}-15(\delta \mathrm{H} 3.49, \mathrm{~m})$ and

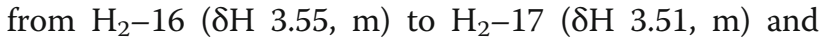
HMBC correlations from $\mathrm{H}_{2}-13(\delta \mathrm{H} 1,07, \mathrm{~m})$ to $\mathrm{C}-15$ ( $\delta \mathrm{C} 166.02)$, from $\mathrm{H}_{2}-14(\delta \mathrm{H} 3.62, \mathrm{~m})$ to $\mathrm{C}-16$ ( $\left.\delta \mathrm{C} 166\right)$, from $\mathrm{H}_{2}-15(\delta \mathrm{H} 3.49, \mathrm{~m})$ to $\mathrm{C}-17(\delta \mathrm{C} 166.01)$ and from $\mathrm{H}_{2}-16(\delta \mathrm{H} 3.55, \mathrm{~m})$ to $\mathrm{C}-18(\delta \mathrm{C} 23.15)$ identified coupled olefins. The key $\mathrm{HMBC}$ correlations from $\mathrm{H}_{2}-$ $1^{\prime}(\delta \mathrm{H} 1.94, \mathrm{~m})$ to $\mathrm{C}-3^{\prime}(\delta \mathrm{C} 23.4)$, from $\mathrm{H}-3^{\prime}(\delta \mathrm{H} 2.14$, m) to $\mathrm{C}-5^{\prime}(\delta \mathrm{C} 29.05)$, from $\mathrm{H}_{3}-14^{\prime}(\delta \mathrm{H} 1.85, \mathrm{~m})$ to $\mathrm{C}-2^{\prime}$ $(\delta \mathrm{C} 215.7)$ and $\mathrm{C}^{\prime} 4^{\prime}-\mathrm{OH}$ ( $\left.\delta \mathrm{C} 73.6\right)$, from $\mathrm{H} 3-15^{\prime}$ $(\delta \mathrm{H} 2.11, \mathrm{~m})$ to $\mathrm{C}-6^{\prime}(\delta \mathrm{C} 215.7)$ and $\mathrm{C}-4^{\prime}-\mathrm{OH}$ identified two meta position carbonyl group and one ortho position hydroxyl group (Fig. 2b).

This connectivity was also secured by the observation of the HSQC correlations from $\mathrm{H}_{3}-14$ ' to $\mathrm{C}-3^{\prime}$ and from $\mathrm{H}_{3}-15^{\prime}$ to $\mathrm{C}-6^{\prime}$. Therefore, the complete structure of naphthoquinone was determined as shown in Fig. 2c.

\section{Physico-chemical characterization of Griseococcin (1)}

Griseococcin (1) was white powder and its solubility was $0.063 \mathrm{~g} / \mathrm{ml}$ in water. It could be slight soluble in methanol and DMSO, but insoluble in $\mathrm{n}$-hexane, dichloromethane, chloroform, ethyl acetate and acetone.

The FT-IR spectrum of Griseococcin (1) showed (Fig. 3) an intense and broad characteristic absorption peaks at $3417.2 \mathrm{~cm}^{-1}$ represented the stretching vibration of $\mathrm{O}-\mathrm{H}$. The weak absorption peaks at 2356 and $2925.5 \mathrm{~cm}^{-1}$ were resulted from the stretching vibration of $\mathrm{C}-\mathrm{H}$. The absorption bands at 1637.4 and 1618.1 $\mathrm{cm}^{-1}$ are due to the vibration of $\mathrm{C}=\mathrm{C}$ and $\mathrm{C}=\mathrm{O}$ in the ester group. The absorptions peaks at 1456.1, 1414 and $624 \mathrm{~cm}^{-1}$ were attributed to the presence of an internal $\mathrm{C}-\mathrm{H}$ deformation. The strong absorption peak at 866 $\mathrm{cm}^{-1}$ was resulted from aromatics. In conclusion, the typical absorption peak indicated that Griseococcin (1) was naphthoquinone with group $\mathrm{O}-\mathrm{H}, \mathrm{C}-\mathrm{H}, \mathrm{C}=\mathrm{C}, \mathrm{C}=\mathrm{O}$ and so on [23].

\section{In vitro antagonistic assay}

Griseococcin (1) was assessed for antimicrobial and microbicidel activity against selected Trichophyton rubrum (ATCC 28188), Trichophyton mentagrophytes (ATCC 9533), Epidermophyton floccosum (ATCC 52066), Candida albicans (ATCC 10231), Staphylococcus aureus (ATCC 6538), Bacillus subtilis (ATCC 6051), Escherichia coli (ATCC 8739) and Pseudomonas aeruginosa (ATCC 27582) The results were shown in Table 1, it displayed strong antifungal activity against T. rubrum, T. mentagrophytes with ZOI values of $18.06 \pm 0.85$, $15.01 \pm 1.02 \mathrm{~mm}$, as compared to the positive control

Table 1 Zone of inhibition (ZOI) of Griseococcin (1) on microbial strains

\begin{tabular}{lllll}
\hline Pathogenic & \multicolumn{2}{l}{ Zone of inhibition $\mathbf{( m m})$} & & \\
\cline { 2 - 5 } & T. rubrum & T. mentagrophytes & Eloccosum & C. albicans \\
\hline Griseococcin (1) & $18.1 \pm 0.9$ & $15.0 \pm 1.0$ & $5.0 \pm 2.3$ & $1.2 \pm 2.2$ \\
Terbinafine & $20.7 \pm 1.6$ & $28.3 \pm 2.2$ & $10.02 \pm 1.02$ & $6.3 \pm 0.6$ \\
& S. aureus & E. coli & B. subtilis & P. aeruginosa \\
Griseococcin (1) & $10.0 \pm 1.9$ & $8.0 \pm 1.1$ & $3.0 \pm 1.2$ & $3.7 \pm 1.4$ \\
Gentamicin sulfate & $31.7 \pm 1.5$ & $28.5 \pm 1.4$ & $10.0 \pm 1.0$ & $33.6 \pm 1.4$ \\
\hline
\end{tabular}




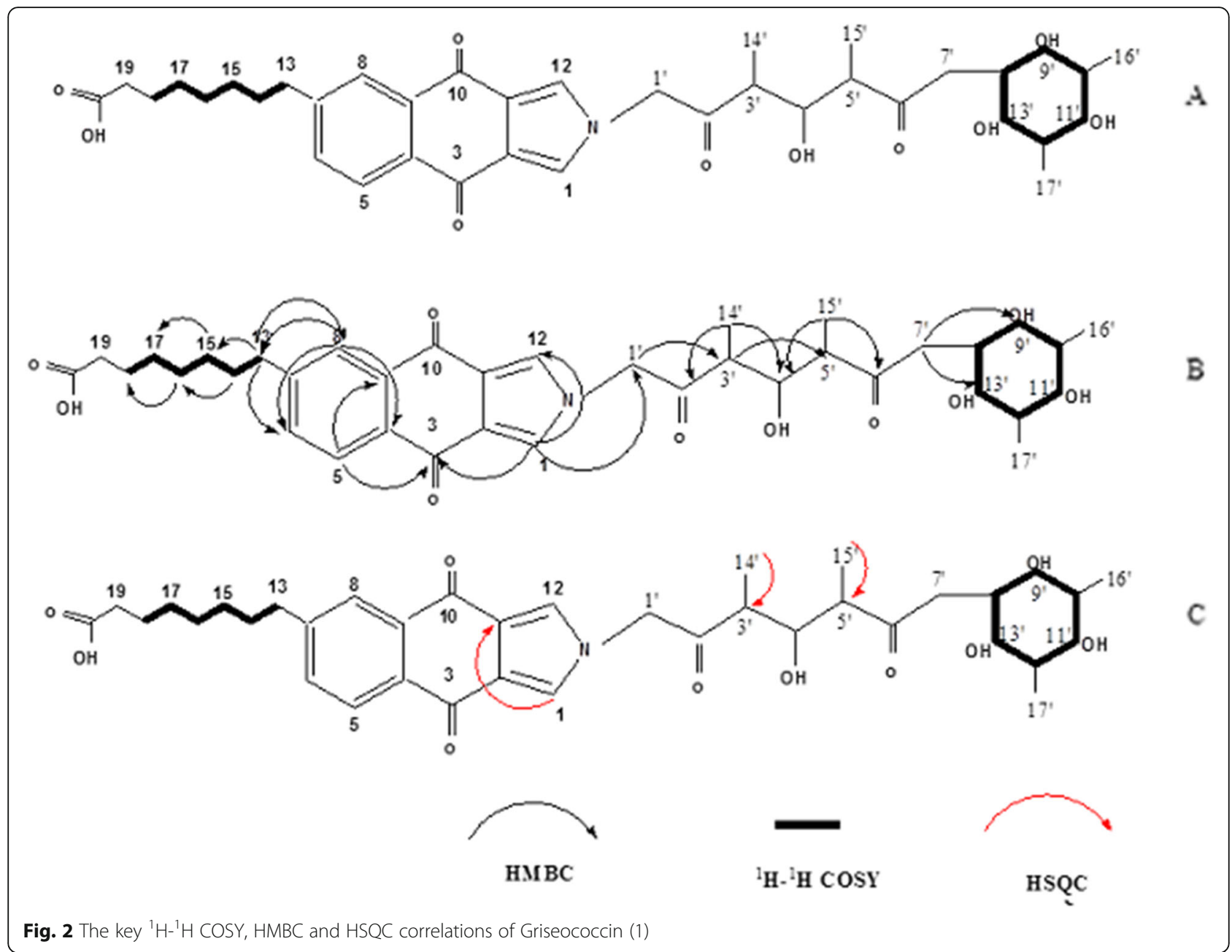

with $\mathrm{ZOI}=20.67 \pm 1.58, \quad 28.33 \pm 2.15 \mathrm{~mm}$, respectively. While antibacterial activity was weak.

J.Meletiadis et al. reported that compounds were considered bactericidal or fungicidal when the $\mathrm{MBC} / \mathrm{MIC}$ or $\mathrm{MFC} / \mathrm{MIC}$ ratio is $\leq 4$ [24]. In this study, it was inportant to discern whether the Griseococcin (1) possesses bactericidal and fungicidal activities. The fungicidal activities of Griseococcin (1) were assessed as MIC, MFC and MFC/MIC. The results were shown in Table 2. Griseococcin (1) showed the high fungicidal activities by means of lowest values of MIC and MFC against the four fungi, especially for main pathogenic fungi ( $T$. rubrum), the MIC, MFC and MFC/MIC values were $31.2 \pm 2.7,31.2 \pm$ $3.1 \mu \mathrm{g} / \mathrm{ml}$ and 1 , while MIC, MFC and MFC/MIC values of Terbinafine were $15.6 \pm 1.2,31.2 \pm 1.6 \mu \mathrm{g} / \mathrm{ml}$ and 6 . Fungicidal activities of Griseococcin (1) are revealed more effective than that of commercial reagents (Terbinafine).

Griseococcin (1) also showed high bactericidal activities with $\mathrm{MIC}, \mathrm{MBC}$ and $\mathrm{MBC} / \mathrm{MIC}$ values ranged between $62.5 \sim 125 \mu \mathrm{g} / \mathrm{ml}, 125-500 \mu \mathrm{g} / \mathrm{ml}$ and $2-4$ against examined bacteria ( $S$. aureus, E. coli and P. aeruginosa). The results were shown in Table 3. Griseococcin (1) showed the highest bactericidal activity for S. aureus and E. coli,. MBC/MIC value of Griseococcin (1) was 2.0, while the $\mathrm{MBC} / \mathrm{MIC}$ ratio was 3.0 and 4.0 for positive control (Gentamicin sulfate).

Due to side effects and the continuous drug resistance, commercial reagents might be unsafe for patients [11], Therefore, the development of fungicidal therapies is crucial, above results (MIC, MFC or MBC and MFC/ $\mathrm{MIC}$ or $\mathrm{MBC} / \mathrm{MIC}$ ) add more value to Griseococcin (1).

\section{Discussion}

In the present study, Griseococcin (1) purified from selected puffball (Bovistella radicata (Mont.) Pat) had remarkable antifungal activities. These data are consistent with previous findings on the minimum inhibitory concentrations (MICs) and zone of inhibition (ZOI) of $B$. radicata fermentation [20].

According to the Chinese Pharmacopeia, the puffball can restrain $S$. aureus and $P$. aeruginosa. The antifungal 


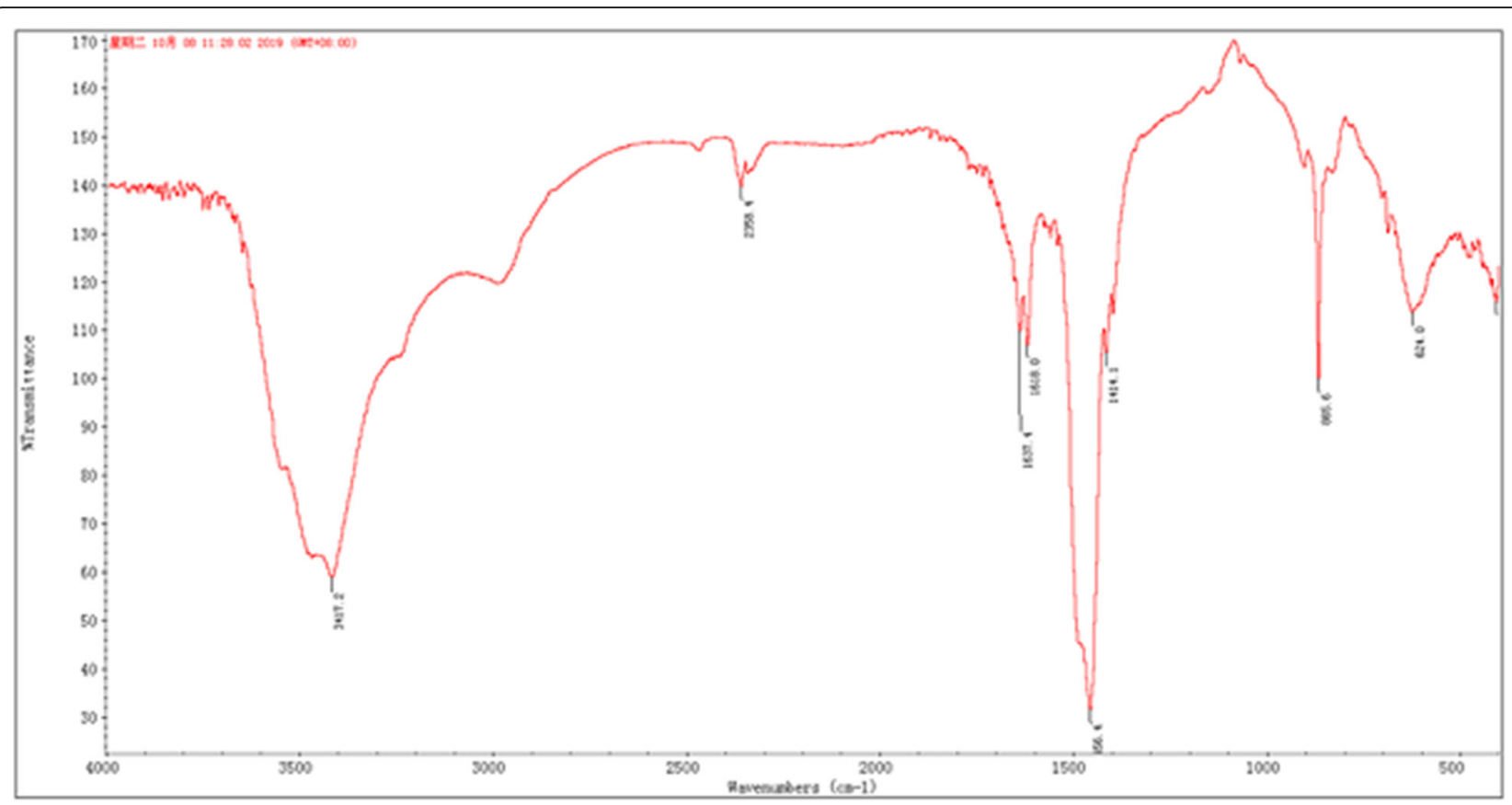

Fig. 3 The FT-IR spectrum of Griseococcin (1)

function of puffball has not been reported previously, hence, the present study is interesting and original. The novel application of $B$. radicata might be due to different geographic sources of the material used and different strains used [25].

In this study, the purification extraction Griseococ$\operatorname{cin}(\mathrm{s})$ from fermentation broth of $B$. radicata obtained through celluous DE-52 and sephadex LH-20 column. In Vitro study on antifungal effects of Griseococcin (1) on fungi showed that the most sensitive fungi strains were the main pathogenic fungi (T. rubrum and T. mentagrophytes) causing tinea pedis, ZOIs were $18.06 \pm 0.85$ and $15.01 \pm 1.02 \mathrm{~mm}$, MICs were $31.2 \pm 2.7$ and $31.2 \pm 1.8 \mu \mathrm{g} /$ $\mathrm{ml}$, MFCs were $31.2 \pm 3.1 \mu \mathrm{g} / \mathrm{ml}$ and $31.2 \pm 2.1 \mu \mathrm{g} / \mathrm{ml}$, MFC/MICs were 1 and 1 against T. rubrum and T. mentagrophytes. ZOI values of positive control (Terbinafine) were $20.67 \pm 1.58 \mathrm{~mm} \quad 28.33 \pm 2.15 \mathrm{~mm}$, MICs were $15.6 \pm 1.6$ and $7.8 \pm 1.2 \mu \mathrm{g} / \mathrm{ml}$, MFCs were $93.6 \pm 2.1$ and $39.0 \pm 2.2 \mu \mathrm{g} / \mathrm{ml}$, MFC/MICs were 6 and 5 respectively. The antifungal effect of Griseococcin (1) was similar with that of positive control, the fungicidal effect of Griseococcin (1) was better than that of positive control. The most sensitive bacterial species for Griseococcin (1) was $S$. aureus and E. coli, MICs and MBCs were $62.5 \pm$ $1.5,125 \pm 2.3$ and $125 \pm 3.1,250 \pm 2.1 \mu \mathrm{g} / \mathrm{ml}$ respectively, $P$. aeruginosa and $B$. subtilis were more resistant. MFC/ MICs and MBC/MICs of Griseococcin (1) were less than positive control which meant that antibacterial activity Griseococcin (1) was better than that of the commercial drugs. This study is important for the development of new drugs with low toxicity, overcoming drug resistance and recurrence.

Table 2 MIC, MFC and MIC/MFC of Griseococcin (1) on fungal strains

\begin{tabular}{lllll}
\hline $\begin{array}{l}\text { Pathogenic } \\
\text { fungi }\end{array}$ & MIC $(\boldsymbol{\mu g} / \mathbf{m l})$ & & \\
\cline { 2 - 5 } & T. rubrum & T. mentagrophytes & C. albicans \\
\hline Griseococcin $(1)$ & $31.2 \pm 2.7$ & $31.2 \pm 1.8$ & $250.0 \pm 5.2$ & $250 \pm 7.6$ \\
MIC $(\mu \mathrm{g} / \mathrm{ml})$ & $31.2 \pm 3.1$ & $31.2 \pm 2.1$ & $500 \pm 3.1$ & $500 \pm 6.7$ \\
MFC $(\mu \mathrm{g} / \mathrm{ml})$ & 1 & 1 & 2 & 2 \\
MFC / MIC & & & & $62.5 \pm 2.1$ \\
Terbinafine & $15.6 \pm 1.6$ & $7.8 \pm 1.2$ & 2.6 & $125 \pm 2.6$ \\
MIC $(\mu \mathrm{g} / \mathrm{ml})$ & $93.6 \pm 2.1$ & $39.0 \pm 2.2$ & $2.0 \pm 2.1$ & 2 \\
MFC $(\mu \mathrm{g} / \mathrm{ml})$ & 6 & 5 & 4 & \\
MFC/ MIC & & & & \\
\hline
\end{tabular}


Table 3 MIC, MBC and MIC/MFC of Griseococcin (1) on bacterial strains

\begin{tabular}{lllll}
\hline $\begin{array}{l}\text { Pathogenic } \\
\text { bacteria }\end{array}$ & \multicolumn{4}{l}{ MIC $(\boldsymbol{\mu g} / \mathrm{ml})$} \\
\cline { 2 - 5 } & S. aureus & E. coli & B. subtilis & P. aeruginosa \\
\hline Griseococcin $(1)$ & & & \\
MIC $(\mu \mathrm{g} / \mathrm{ml})$ & $62.5 \pm 1.5$ & $125 \pm 2.3$ & $125 \pm 1.5$ & $62.5 \pm 3.6$ \\
MBC $(\mu \mathrm{g} / \mathrm{ml})$ & $125 \pm 3.1$ & $250 \pm 2.1$ & $>500$ & $250 \pm 6.7$ \\
MBC / MIC & 2.0 & 2.0 & $>4.0$ & 4.0 \\
Gentamicin sulfate & & & \\
MIC $(\mu \mathrm{g} / \mathrm{ml})$ & $15.6 \pm 1.3$ & $31.2 \pm 2.4$ & $31.2 \pm 3.0$ & $62.5 \pm 2.6$ \\
MBC $(\mu \mathrm{g} / \mathrm{ml})$ & $46.8 \pm 1.6$ & $124.8 \pm 2.2$ & $202.8 \pm 2.1$ & $350 \pm 2.2$ \\
MBC/MIC & 3.0 & 4.0 & 6.5 & 5.6 \\
\hline
\end{tabular}

The FT-IR spectrum of Griseococcin (1) showed the strong absorption band, stretching vibration and bending vibration of $\mathrm{O}-\mathrm{H}, \mathrm{C}=\mathrm{O}, \mathrm{C}=\mathrm{C}$ and $\mathrm{C}-\mathrm{H}$ which belong to a unsaturated coupled bond and aromatic form of naphthoquinone. According to HR-ESI-MS analysis, MW of Griseococcin (1) was $661 \mathrm{Da}$. Based on the results of different spectral (HPLC, FT-IR, DSC, 1D and 2D NMR etc.) studies and physicochemical properties, the molecular formula of Griseococcin (1) was $\mathrm{C}_{37} \mathrm{H}_{43} \mathrm{NO}_{10}$ and the molecular structure of Griseococcin (1) was shown in Fig. 1. MBC/MICs of were 6 and 5 respectively.

Previously, many authors reported the various biological activity of fermentation broth from puffball like anticancer activity [26, 27], antioxidant activity [28], antifatigue effect [29], etc. In the present study, the antifungal activity of $B$. radicata was another important biological function. The biological activities of organic compounds are related to their molecular weight, functional groups, the length of chain, the composition of group and the number of branches, hydrophilic and hydrophobic group. It means that the structure-activity relationship should be disclosed.

\section{Conclusions}

Future work concentrating on determining the antifungal mechanisms of Griseococcin (1) will be performed, which will be helpful in laying a foundation for overcoming the drug resistance that pathogens quickly develop against tinea pedis.

In this paper, the antifungal secondary metabolite compound Griseococcin (1) from B. radicata were studied. The compound from Bovistella radicata (Mont.) Pat was purified. Molecular weight and molecular formula of the purified compound (Griseococcin (1)) were $661 \mathrm{Da}$ and $\mathrm{C}_{37} \mathrm{H}_{43} \mathrm{NO}_{10}$ respectively, it can restrain main pathogens ( $T$. rubrum and T. mentagrophytes) leading to tinea pedis. The antifungal activity of Griseococcin (1) was similar to that of the positive control.

\section{Methods}

Sample Bovistella radicata (Mont.) Pat collection and tested microorganisms

Bovistella radicata (Mont.) Pat was obtained from Shuinan town, Jishui county, Jiangxi province, China. After strain identification and authenticated by Professor Qingmei Zeng, it belongs to Agaricalesorder, Lycoperdaceae family, Bovistella genus, Bovistella radicata (Mont.) Pat species. The tested pathogenic fungi included Trichophyton rubrum (ATCC 28188), Trichophyton mentagrophytes (ATCC 9533), Epidermophyton floccosum (ATCC 52066), and Candida albicans (ATCC 10231). Four strains of test pathogenic bacteria included Staphylococcus aureus (ATCC 6538), Bacillus subtilis (ATCC 6051), Escherichia coli (ATCC 8739) and Pseudomonas aeruginosa (ATCC 27582). All standard bacterial and fungal strains were obtained from rom the Microbiology Laboratory at Department of Biology, Anhui Medical University, Anhui.

\section{Fermentation, extraction and purification of Bovistella radicata (Mont.) Pat}

The mature B.radicata should be dried at $40^{\circ} \mathrm{C}$ for at least 2 days, and taken out when its weight is no longer changed, the sporophore and spore powder were ground together and filtered through a 100 mesh sieve. The mixed powder of B.radicata was inoculated into $100 \mathrm{~mL}$ of potato dextrose broth (PDB) in $250 \mathrm{ml}$ flask. The flask was kept in rotary shaker at $25^{\circ} \mathrm{C}$ with $115 \mathrm{rpm}$ for $72 \mathrm{~h}$. The $\mathrm{pH}$ and moisture content of PDB was also determined according Maguireboyle (2014) and Mcauliffe (2016) [30, 31]. For every $12 \mathrm{~h}$, the fermentation was taken to perform antimicrobial activity against main pathogens $T$. rubrum and $T$. mentagrophytes by zone of inhibition (ZOI) method. Then the fermentation were centrifuged at 7000 rpm for $20 \mathrm{~min}$ and filtered over Whatman No.4 paper to get the final clear supernatant and preserve at $4{ }^{\circ} \mathrm{C} .50 \mathrm{ml}$ clear supernatant was purified firstly using $100 \mathrm{ml}$ DEAEcellulose column and eluted by different concentration $\mathrm{NaCl}(10-30 \%)$ to get different fractions. $20 \% \mathrm{NaCl}$ elution fraction showed best antifungal activity against pathogens and was named as SPAF. Furthermore, SPAF $(20 \%$ $\mathrm{NaCl}$ elution fraction) was purified by sephadex LH-20 column. Different purified fractions (named Griseococ$\operatorname{cin}(\mathrm{s}))$ were obtained from SPAF, only Griseococcin(1) $(500 \mu \mathrm{g} / \mathrm{ml})$ has antifungal activity and it's biochemical characteristics and spectral (HPLC, FT-IR, 1D and 2D NMR etc.) studies were assessed.

\section{Antimicrobial activity}

The examined methods were the minimum inhibitory concentrations (MICs) [22], minimum bactericidal concentration (MBCs) or minimum fungicidal concentration (MFCs) [32, 33] and zone of inhibitions (ZOIs) [34]. 
$\mathrm{ZOI}$ is qualitative analysis and MIC is quantitative analysis of antimicrobial activity [35]. The MICs, MBCs and MFCs of Griseococcin (1) were determined in the 96well plates by the double micro dilution method against pathogens. $100 \mu \mathrm{L}$ dilutions (approximately $10^{6} \mathrm{CFU} /$ $\mathrm{mL}$ ) of T. rubrum, T. mentagrophytes, E. floccosum, and C. albicans in potato dextrose broth and S. aureus, B. subtilis, E. coli and P. aeruginosa in Nutrient Broth [36] were inoculated into 96-well plates. Then, $100 \mu \mathrm{L}$ Griseococcin (1) solutions were added after a double dilution with the corresponding medium broth (from $500 \mu \mathrm{g} / \mathrm{mL}$ to $7.8 \mu \mathrm{g} / \mathrm{mL}$ ). $0.9 \%$ (v/v) $\mathrm{NaCl}$ was used as the negative control. Gentamicin sulfate or Terbinafine were dissolved in normal saline (NS) to a concentration of $1 \mathrm{mg} / \mathrm{mL}$ for the subsequent tests as positive control against bacteria or fungi. The Petri dishes were incubated at $37^{\circ} \mathrm{C}$ for $24 \mathrm{~h}$ with S. aureus, E. coli, B. subtilis and $P$. aeruginosa, for $48 \mathrm{~h}$ with T. rubrum, T. mentagrophytes, E. floccosum, and C. albicans. Griseococcin (1) was also dissolved in NS at $1 \mathrm{mg} / \mathrm{mL}$. The MIC was recorded as the lowest concentration of sample showing no detectable growth. MFC or MBC was determined as the concentration causing no visible growth and killing $99.5 \%$ of the original inoculum. Ten microliters of subinhibitory concentrations of Griseococcin (1) was placed in the corresponding solid medium for $48 \mathrm{~h}$ to determine the MBC or MFC values according to the growth of the microbial colonies. Each sample was performed twice. The zones of inhibition (ZOI) of Griseococcin (1) $(100 \mu \mathrm{g} / \mathrm{ml})$ was also evaluated. The prepared Griseococcin (1) was filled into the wells. After incubating for $24 \mathrm{~h}$ at $37^{\circ} \mathrm{C}$, the measurements were done basically from the edge of the zone to the edge of the well [34].

\section{General experimental procedures}

The $\mathrm{UV}_{\max }$ absorption spectrum of SPAF was analyzed at full-wave spectra $(200-900 \mathrm{~nm})$ by UV/vis $2802 \mathrm{spec}-$ trophotometer. The FT-IR spectrum of Griseococcin(s) were recorded on a Thermo Nicolet Spectrum FT-IR in a range of $4000-400 \mathrm{~cm}^{-1}$ with $\mathrm{KBr}$ pellets. HR-ESI-MS data were obtained on an Agilent 1260 Infinity LC coupled to a 6230 TOF. $20 \mathrm{mg}$ of the dried sample was dissolved in $0.55 \mathrm{~mL}$ of deuteroxide $(99.99 \% \mathrm{D})$ in a NMR tube. 1D and 2D NMR spectra were acquired on an AVANCE-600 NMR spectrometer (Bruker Inc., Rheinstetten, Germany) at $50^{\circ} \mathrm{C}$. The chemical shifts were given in $\delta(\mathrm{ppm})$ and referenced to the solvent signal $\left(\mathrm{D}_{2} \mathrm{O}-\mathrm{d}_{6}, \delta \mathrm{H}\right.$ 2.50, $\delta \mathrm{C}$ 39.5). Column chromatography (CC) was conducted on DEAE-cellulose and Sephadex LH-20. The fractions Griseococcin(s) were also monitored by HPLC (Agilent 1260 chromatography system, USA) which was equipped with a diode array detector (DAD). The DAD detector was set at $215 \mathrm{~nm}$ to acquire chromatograms. The separation of the
Table $4{ }^{1} \mathrm{H}(700 \mathrm{MHz})$ and ${ }^{13} \mathrm{CNMR}(175 \mathrm{MHz})$ spectroscopic data for Griseococcin (1): in DMSO

\begin{tabular}{|c|c|c|}
\hline Position & $\delta \mathrm{H}$ (mult, J inHz) & $\delta C$ \\
\hline 1 & 7.81 & 166 \\
\hline 2 & & 128.56 \\
\hline 3 & & 175.11 \\
\hline 4 & & 138.60 \\
\hline 5 & 7.93 & 135.7 \\
\hline 6 & 7.72 & 137.21 \\
\hline 7 & & 136.28 \\
\hline 8 & 7.80 & 135.45 \\
\hline 9 & & 138.56 \\
\hline 10 & & 175.07 \\
\hline 11 & & 128.57 \\
\hline 12 & 7.66 & 166.07 \\
\hline 13 & 1.07 & 30.18 \\
\hline 14 & 3.62 & 166.01 \\
\hline 15 & 3.49 & 166.02 \\
\hline 16 & 3.55 & 166.03 \\
\hline 17 & 3.51 & 166.01 \\
\hline 18 & 1.25 & 23.15 \\
\hline 19 & 1.94 & 23.16 \\
\hline 20 & 2.09 & 184.15 \\
\hline $1^{\prime}$ & 1.94 & 28.4 \\
\hline $2^{\prime}$ & & 215.7 \\
\hline $3^{\prime}$ & 2.14 & 23.4 \\
\hline $4^{\prime}$ & 4.47 & 73.6 \\
\hline $4^{\prime}-\mathrm{OH}$ & 8.37 & \\
\hline $5^{\prime}$ & 2.12 & 29.05 \\
\hline $6^{\prime}$ & & 215.7 \\
\hline $7^{\prime}$ & 1.08 & 25.52 \\
\hline $8^{\prime}$ & 1.94 & 26.81 \\
\hline $9^{\prime}$ & 3.62 & 71.25 \\
\hline $9^{\prime}-\mathrm{OH}$ & 7.81 & \\
\hline $10^{\prime}$ & 1.29 & 23.45 \\
\hline $11^{\prime}$ & 3.49 & 71.15 \\
\hline $11^{\prime}-\mathrm{OH}$ & 7.80 & \\
\hline $12^{\prime}$ & 1.73 & 23.47 \\
\hline $13^{\prime}$ & 3.51 & 71.18 \\
\hline $13^{\prime}-\mathrm{OH}$ & 7.93 & \\
\hline $14^{\prime}$ & 1.85 & $20.27 \mathrm{CH}_{3}$ \\
\hline $15^{\prime}$ & 2.11 & $20.27 \mathrm{CH}_{3}$ \\
\hline $16^{\prime}$ & 1.06 & $20.27 \mathrm{CH}_{3}$ \\
\hline $17^{\prime}$ & 1.07 & $20.27 \mathrm{CH}_{3}$ \\
\hline
\end{tabular}


compound was performed on a Hypersil RP-C18 column $(5 \mu \mathrm{m}, 250 \times 10.0 \mathrm{~mm}$, Thermo Fisher Scientific, USA) at a temperature of $25^{\circ} \mathrm{C}$. Injection volume: $20 \mu \mathrm{L}$.

\section{Griseococcin (1)}

Griseococcin (1): IR (neat) v $\max 3417,2926,2356$, $1637,1618,1456,1414,866,624 \mathrm{~cm}^{-1}$; UV $\left(\mathrm{D}_{2} \mathrm{O}\right) \lambda \max$ $215 \mathrm{~nm} ;{ }^{1} \mathrm{H}$ and ${ }^{13} \mathrm{CNMR}$ data see Table 4; HR-ESI-MS $\mathrm{m} / \mathrm{z} \quad 661.1970[\mathrm{M}+\mathrm{H}]+$ (calcd for $\mathrm{C}_{37} \quad \mathrm{H}_{43} \mathrm{NO}_{10}$, 661.1968).

\section{Supplementary information}

Supplementary information accompanies this paper at https://doi.org/10. 1186/s12866-020-01961-X.

\section{Additional file 1.}

\section{Abbreviations}

NMR: Nuclear Magnetic Resonance; HPLC: High Performance Liquid Chromatography; FT-IR: Fourier transform infrared spectroscopy; DMSO: Dimethyl Sulfoxide; ZOI: Zone of inhibition; MIC: Minimum inhibitory concentration; HR-ESI-MS: High-resolution electrospray ionization mass spectroscopy; DAD: Diode array detector; MW: Molecular weight

\section{Acknowledgements}

Not applicable.

\section{Authors' contributions}

YY conceived and designed the experiments, performed the experiments and analyzed the data, wrote and edited the manuscript. QZ1 analyzed the data. The excellent technical support by QZ2. All authors read and approved the final manuscript

\section{Funding}

This study was supported by the National Natural Science Foundation of China (NSFC) (Grant No. 31371844; 31071556) and the Science and Technology Department of Anhui province, PR of China (Grant No. 130103215). NSFC did not have a role in the design of the study, in the collection, analysis, or interpretation of the data, or in writing the manuscript.

\section{Availability of data and materials}

The datasets used and analysed during the current study are available from the corresponding author on resonable request.

\section{Ethics approval and consent to participate}

Not applicable.

\section{Consent for publication}

Not applicable.

\section{Competing interests}

The authors declare that they have no competing interests.

Received: 14 May 2020 Accepted: 1 September 2020

Published online: 10 September 2020

\section{References}

1. Alteras I, Cafri B, Feuerman EJ. The high incidence of Tinea pedis and unguium in patients with Kaposi's sarcoma. Mycopathologia. 1981;74(3):1779.

2. Koltin $Y$, Hitchcock CA. The search for new triazole antifungal agents. Curr Opin Chem Biol. 1997;1(2):176-82.

3. Erbagci Z, Tuncel A, Zer Y, Balci I. A prospective epidemiologic survey on the prevalence of onychomycosis and dermatophytosis in male boarding school residents. Mycopathologia. 2005;159(3):347-52.
4. Miyajima Y, Satoh K, Uchida T, Yamada T, Abe M. Rapid real-time diagnostic PCR for Trichophyton rubrum and Trichophyton mentagrophytes in patients with tinea unguium and tinea pedis using specific fluorescent probes. J Dermatol Sci. 2013;69(3):229-35.

5. Daneshmend DTK, Warnock DW. Clinical pharmacokinetics of systemic antifungal drugs. Clin Pharmacokinet. 1983;8(1):17-42.

6. Patel VM, Schwartz RA, Lambert WC. Topical antiviral and antifungal medications in pregnancy: a review of safety profiles. J Eur Avad Dermatol. 2017;31(9):350-6.

7. Francis P, Walsh TJ. Evolving role of Flucytosine in Immunocompromised patients: new insights into safety, pharmacokinetics, and antifungal therapy. Clin Infect Dis. 1992;15(6):1003-18.

8. Stamm AM, Diasio RB, Dismukes WE, Shadomy SM, Cloud GA. Toxicity of amphotericin B plus flucytosine in 194 patients with cryptococcal meningitis. Am J Med. 1987;83(2):236-42.

9. Vermes A, Guchelaar HJ, Dankert J. Flucytosine: a review of its pharmacology, clinical indications, pharmacokinetics, toxicity and drug interactions. J Antimicrob Chemother. 2000;46(2):171-9.

10. Denning DW, Venkateswarlu K, Oakley KL, Anderson MJ, Manning NJ. Itraconazole resistance in Aspergillus fumigatus. Antimicrob Agents Ch. 1997; 41(6):1364-8.

11. Subissi A, Monti D, Togni G, Mailland F. Ciclopirox: recent nonclinical and clinical data relevant to its use as a topical antimycotic agent. Drugs. 2010; 70(16):2133-52.

12. Lushchak VI. Contaminant-induced oxidative stress in fish: a mechanistic approach. Fish Physiol Biochem. 2016;42(2):711-47.

13. Rajendra U, Campbell LT, Donlin MJ, Aurora R, Lodge JK. Global Transcriptome profile of Cryptococcus neoformans during exposure to hydrogen peroxide induced oxidative stress. PLoS One. 2013;8(1):e55110.

14. Genilloud $\mathrm{O}$. The reemerging role of microbial natural products in antibiotic discovery. Anton Leeuw Int J G. 2014;106:173-88.

15. Ribeiro WLC, Macedo ITF, Rondon FCM, Bevilaqua CML. Essential oils and their bioactive compounds in the control of gastrointestinal nematodes of small ruminant. Acta Sci Vet. 2018;46(1522):1-14.

16. Bates ST, Roberson RW, Desjardin DE. Arizona gasteroid fungi I: Lycoperdaceae (Agaricales, Basidiomycota). Fungal Divers. 2009;37(37):153207.

17. Liang Y. Hemostatic material for use in variety of fresh tissue trauma, comprises microporous starch, hyaluronic acid, collagen and puffball spores at specific weight percentage; 2016. CN105664233-A.

18. Jiang K. Beverage useful for relieving cough, moisturizing lungs and improving immunity, contains Asparagus, coltsfoot, Sonchus arvensis, maidenhair, lotus seed, corni fructus, puffball, galangal, boneset, club moss herb, sugar and preservative; 2017. CN,CN106729277-A.

19. Lam YW, Ng TB, Wang HX. Antiproliferative and Antimitogenic activities in a peptide from puffball mushroom Calvatia caelata. Biochem Bioph Res Co. 2001:289(3):744-9.

20. Ye Y, Liu K, Zeng QH, Zeng QM. Antimicrobial activity of puffball (Bovistella radicata) and separation of bioactive compounds. AMB Express. 2017;7(1):99.

21. Negi PS, Anandharamakrishnan C, Jayaprakasha GK. Antibacterial activity of Aristolochia bracteata root extracts. J Med Food. 2003;6(4):401-3.

22. Petrović P, Vunduk J, Klaus A, Kozarski M, Nikšić M. Biological potential of puffballs: a comparative analysis. J Funct Foods. 2016;21:36-49.

23. Xie J, Zou L, Luo X. Structural characterization and immunomodulating activities of a novel polysaccharide from Nervilia fordii. Int J Biol Macromol. 2018;1:114-20.

24. Meletiadis J, Antachopoulos C, Stergiopoulou T, et al. Differential fungicidal activities of amphotericin B and Voriconazole against Aspergillus species determined by microbroth methodology. Antimicrob Agents Chemother. 2007;51(9):3329-37.

25. Ali NAA, Mothana RAA, Lesnau A, Pilgrim H, Lindequist U. Antiviral activity of Inonotus hispidus. Fitoterapia. 2003;74(5):483-5.

26. Silva JP, Alves C, Pinteus S. Antioxidant and antitumor potential of wild and IMTA-cultivated Osmundea pinnatifida. J Oceanol Limol. 2019;37(3):825-35.

27. Zhong M, Zhong C, Hu P. Restoration of stemness-high tumor cellmediated suppression of murine dendritic cell activity and inhibition of tumor growth by low molecular weight oyster polysaccharide [J]. Int Immunopharmacol. 2018;65:221-32.

28. Xu C, Qiao L, Guo Y. Preparation. Characteristics and antioxidant activity of polysaccharides and proteins-capped selenium nanoparticles synthesized by Lactobacillus casei ATCC 393.[J]. Carbohydr Polym. 2018;195:576-85. 
29. Yange L, Lanzhou L, Shengshu A, et al. Antifatigue effects of Antrodia cinnamomea cultured mycelium via modulation of oxidative stress signaling in a mouse model. Biomed Res Int. 2017;2017:9374026. https://doi.org/10. 1155/2017/9374026 Accessed 23 Mar 2017.

30. Maguireboyle SJ, Barron AR. Organic compounds in produced waters from shale gas wells. Environ Sci-Proc Imp. 2014;16(10):2237.

31. Mcauliffe LN, Kilcawley KN, Sheehan JJ. Manufacture and incorporation of liposome-entrapped ethylenediaminetetraacetic acid into model miniature gouda-type cheese and subsequent effect on starter viability, pH, and moisture content. J Food Sc. 2016;81(11):C2708-17.

32. Xue $P$, Yang $X$, Sun $X$, et al. Antifungal activity and mechanism of heattransformed ginsenosides from notoginseng against Epidermophyton floccosum, Trichophyton rubrum, and Trichophyton mentagrophytes. RSC Adv. 2017;7(18):10939-46.

33. Ren $G$, Xue $P$, Sun $X$, et al. Determination of the volatile and polyphenol constituents and the antimicrobial, antioxidant, and tyrosinase inhibitory activities of the bioactive compounds from the by-product of Rosa rugosa Thunb. Var. plena regal tea. BMC Complement Altern Med. 2018;18(1):307-16.

34. Geetha R, Sathian CT, Prasad V, Gleeja VL. Efficacy of purified antimicrobial peptides from lactic acid bacteria against bovine mastitis pathogen. Asian J Dairy Food Res. 2015;34:259-64.

35. Dharajiya D, Patel P, Moitra N. Antibacterial activity of Emblica officinalis (Gaertn.) fruits and Vitex negundo (L.) leaves. Curr Trends Biotechnol Pharm. 2015;9:357-68

36. Hopper S. Standard methods for the examination of dairy products, vol. 11. 11th ed. Washington, DC: American Public Health Association; 1999. p. 940-1.

\section{Publisher's Note}

Springer Nature remains neutral with regard to jurisdictional claims in published maps and institutional affiliations.

Ready to submit your research? Choose BMC and benefit from:

- fast, convenient online submission

- thorough peer review by experienced researchers in your field

- rapid publication on acceptance

- support for research data, including large and complex data types

- gold Open Access which fosters wider collaboration and increased citations

- maximum visibility for your research: over $100 \mathrm{M}$ website views per year

At $\mathrm{BMC}$, research is always in progress.

Learn more biomedcentral.com/submissions 